\title{
Phylogenetic Evidence for Sphingomonas and Rhizomonas as Nonphotosynthetic Members of the Alpha-4 Subclass of the Proteobacteria
}

\author{
MARIKO TAKEUCHI, ${ }^{1 *}$ HIROYUKI SAWADA, ${ }^{2} \dagger$ HIROSHI OYAIZU, ${ }^{3}$ AND AKIRA YOKOTA ${ }^{1}$ \\ Institute for Fermentation, Osaka, Yodogawa-ku, Osaka 532, ${ }^{1}$ Akitsu Branch, Fruit Tree Research Station, \\ Ministry of Agriculture, Forestry and Fisheries, Akitsu, Hiroshima $729-24,{ }^{2}$ and Faculty of \\ Agriculture, The University of Tokyo, Bunkyo-ku, Tokyo $113,{ }^{3}$ Japan
}

\begin{abstract}
To clarify the taxonomic relationships of the genera Rhizomonas and Sphingomonas, the 16S rRNA sequence of Rhizomonas suberifaciens IFO $15211^{\mathrm{T}}$ ( $\mathrm{T}=$ type strain) was determined. A phylogenetic analysis of aligned 16S rRNA gene sequences revealed that eight species of the genus Sphingomonas and $R$. suberifaciens are closely related to Erythrobacter longus and Porphyrobacter neustonensis and, therefore, belong in the alpha-4 subclass of the Proteobacteria. Within this subclass, Sphingomonas species and $R$. suberifaciens are phylogenetically interrelated and comprise several subgroups. Our findings show that the genus and species definitions of these organisms are in need of revision.
\end{abstract}

The genus Sphingomonas, whose type species, Sphingomonas paucimobilis, was previously named Pseudomonas paucimobilis Holmes et al. (6), was proposed by Yabuuchi et al. (42) for yellow-pigmented, motile rods with single polar flagella and nonmotile, nonfermentative, gram-negative rods. Sphingomonas paucimobilis contains large amounts of a unique sphingoglycolipid with the long-chain base dihydrosphingosin, 2-hydroxymyristic acid $(41,43)$, and isoprenoid quinone Q-10. Five species, Sphingomonas paucimobilis, Sphingomonas parapaucimobilis, Sphingomonas yanoikuyae, Sphingomonas adhaesiva, and Sphingomonas capsulata, were described by Yabuuchi et al. (42). Recently, we described three new species of the genus Sphingomonas, Sphingomonas sanguis, Sphingomonas macrogoltabidus, and Sphingomonas terrae (29). Sphingomonas sanguis is the new species name proposed for Sphingomonas genospecies 1 of Yabuuchi et al. (42). Sphingomonas macrogoltabidus and Sphingomonas terrae are polyethylene glycolutilizing bacteria $(11,12)$ which were previously classified as Flavobacterium species. Polyethylene glycol 4000 is utilized by a single bacterium, Sphingomonas terrae, but polyethylene glycol 6000 is utilized by symbiotic mixed cultures of two strains (13), and the dominant bacterium in the mixed cultures is Sphingomonas macrogoltabidus.

Recently, we compared the 16S rRNA sequences of the eight previously described and newly proposed species of the genus Sphingomonas with the $16 \mathrm{~S}$ rRNA sequences of 15 representative species belonging to the alpha subclass of the Proteobacteria (29), and we found that the eight Sphingomonas species form a large and heterogeneous cluster which is clearly separate from all other representatives of the alpha subclass of the Proteobacteria $(26,38)$ except Erythrobacter longus $(23,24)$.

On the other hand, the genus Rhizomonas and the single species Rhizomonas suberifaciens were proposed by van Bruggen et al. (32) for the gram-negative, motile, rod-shaped bacteria that cause corky root of lettuce. Most strains of Rhizomonas suberifaciens are oligotrophic (31), but the morphological, physiological, and chemotaxonomic characteristics

\footnotetext{
* Corresponding author. Mailing address: Institute for Fermentation, Osaka, 17-85, Juso-honmachi 2-chome, Yodogawa-ku, Osaka 532, Japan. Phone: 06-300-6555. Fax: 06-300-6814.

$\dagger$ Present address: National Institute of Agro-Environmental Sciences, 3-1-1, Kannondai, Tsukuba, Ibaraki 305, Japan.
}

of these organisms are similar to those reported for Sphingomonas paucimobilis $(33,42)$. Neither Rhizomonas suberifaciens nor Sphingomonas paucimobilis produces acid on peptone-glucose medium, but both organisms produce acid on ammonium or nitrate-glucose medium (6). Strains of these two species have the same isoprenoid quinone (ubiquinone 10) and similar fatty acid compositions $(8,17,33)$, and the results of grouping based on these two characteristics have been shown to coincide with the results of grouping based on rRNA-DNA homology data (33).

On the basis of these findings, we suggested previously that species belonging to the genera Sphingomonas and Rhizomonas are closely related to each other (29).

Recently, on the basis of sequencing data for 270 bases of 16S rRNA genes from eight strains of Rhizomonas species and eight strains of Sphingomonas species, van Bruggen et al. (33) reported that Sphingomonas yanoikuyae is more closely related to Rhizomonas suberifaciens than to other Sphingomonas species and should be transferred to the genus Rhizomonas and that Sphingomonas capsulata should be removed from the genus Sphingomonas and placed in a separate genus.

In order to investigate the phylogenetic interrelationships of these organisms, we determined the 16S rRNA gene sequence and chemotaxonomic characteristics of Rhizomonas suberifaciens and compared the resulting data with data for Sphingomonas species, Erythrobacter longus, and other members of the alpha subclass of the Proteobacteria.

In this paper we describe the 16S rRNA sequence of Rhizomonas suberifaciens and phylogenetic evidence which indicates that the genera Sphingomonas and Rhizomonas are nonphotosynthetic members of the alpha-4 subclass of the Proteobacteria.

\section{MATERIALS AND METHODS}

Cultures. Rhizomonas suberifaciens IFO $15211^{\mathbf{T}}$ (= ATCC $49355^{\mathrm{T}}=$ NCPPB $\left.3629^{\mathrm{T}}\right)(\mathrm{T}=$ type strain $)$ and IFO $15212(=$ ATCC $49382=$ NCPPB 3631 ) were cultured at $28^{\circ} \mathrm{C}$ in shake flasks containing (per liter) $5.0 \mathrm{~g}$ of peptone, $2.5 \mathrm{~g}$ of glucose, $1.3 \mathrm{~g}$ of $\mathrm{K}_{2} \mathrm{HPO}_{4}, 0.5 \mathrm{~g}$ of $\mathrm{MgSO}_{4} \cdot 7 \mathrm{H}_{2} \mathrm{O}, 0.5 \mathrm{~g}$ of $\mathrm{KNO}_{3}$, and $0.06 \mathrm{~g}$ of $\mathrm{Ca}\left(\mathrm{NO}_{3}\right)_{2} \cdot 4 \mathrm{H}_{2} \mathrm{O}$ (pH 7.2) (PG medium). Erythrobacter longus IFO $14126^{\mathrm{T}}$ (= ATCC $33941^{\mathrm{T}}$ ) was cultivated in seawater medium containing (per liter) $4.0 \mathrm{~g}$ of peptone, 2.0 
TABLE 1. Comparison of morphological, physiological, and biochemical characteristics of the genera Sphingomonas and Rhizomonas

\begin{tabular}{|c|c|c|}
\hline Characteristic & Sphingomonas ${ }^{a}$ & Rhizomonas \\
\hline Plant pathogenicity & $-{ }^{b}$ & $+^{c}$ \\
\hline Oligotroph & - & $\mathrm{v}^{c}$ \\
\hline \multicolumn{3}{|l|}{ Morphological characteristics } \\
\hline Cell shape & Rods & Rods \\
\hline Color of colonies & Yellow or whitish yellow & Yellow or whitish yellow \\
\hline Motility & $\mathrm{v}$ & $\mathrm{v}$ \\
\hline Flagellum & Single, polar & Single, lateral, subpolar, or polar \\
\hline \multicolumn{3}{|l|}{ Physiological characteristics } \\
\hline Oxidase & + & + \\
\hline Catalase & + & + \\
\hline Acid produced from glucose & + & + \\
\hline Arginine dihydrolase & - & - \\
\hline Nitrate reduction & $\mathrm{v}$ & + \\
\hline Bacteriochlorophyll $a$ & - & - \\
\hline \multicolumn{3}{|l|}{ Chemical characteristics } \\
\hline Isoprenoid quinone & Q-10 & Q-10 \\
\hline \multicolumn{3}{|l|}{ Major cellular fatty acids } \\
\hline Nonpolar fatty acid & $18: 1$ & $18: 1$ \\
\hline 2-Hydroxy fatty acids & $14: 0,15: 0,16: 0$ & $14: 0,15: 0$ \\
\hline 3-Hydroxy fatty acid & - & - \\
\hline Sphingolipids & $+(d-18: 0, d-19: 1, d-20: 1, d-21: 1)$ & $+(\mathrm{d}-18: 0, \mathrm{~d}-20: 1 \mathrm{~d}-21: 1)$ \\
\hline LPS & - & $-d$ \\
\hline $\mathrm{G}+\mathrm{C}$ content $(\mathrm{mol} \%)$ & $61.6-67.8$ & $58.0-63.0$ \\
\hline
\end{tabular}

${ }^{a}$ Data from references 29 and 42 .

$b+$, all strains are positive; - , all strains are negative; $v$, variable from strain to strain.

"Data from reference 33 .

${ }^{d}$ All strains are positive according to van Bruggen et al. (33).

g of yeast extract, $10 \mathrm{mg}$ of $\mathrm{FeSO}_{4} \cdot 7 \mathrm{H}_{2} \mathrm{O}, 750 \mathrm{ml}$ of seawater, and enough distilled water to bring the volume up to $1,000 \mathrm{ml}$ $(23,24)$.

Cellular lipids and fatty acid analysis. Cells were harvested after they were cultured for $24 \mathrm{~h}$ in PG medium and freezedried, and then $50 \mathrm{mg}$ of dried cells was mixed with $2 \mathrm{ml}$ of $5 \%$ $\mathrm{HCl}$ in methanol and the preparation was heated at $100^{\circ} \mathrm{C}$ for 3 h. Fatty acid methyl esters were extracted with $n$-hexane and were separated by thin-layer chromatography by using an $n$-hexane-diethyl ether $(1: 1, \mathrm{vol} / \mathrm{vol})$ solvent system. Nonpolar acids and 2-hydroxy and 3-hydroxy fatty acids, visualized by spraying plates $0.02 \%$ dichlorofluorescein in ethanol, were extracted with diethyl ether and analyzed by gas-liquid chromatography as described previously (29). The long-chain bases of the cellular sphingolipids were obtained from acid hydrolysates of dried cells as described by Yano et al. (44). The bases were then subjected to thin-layer chromatography by using a of chloroform-methanol-water $(65: 25: 4$, vol/vol) solvent system and analyzed as trimethylsilyl ethers by gas chromatographymass spectrometry.

Analysis of bacteriochlorophyll. Bacteriochlorophyll was extracted from dried cells with methanol by the method of Stal et al. (28). Samples were extracted twice for $2 \mathrm{~h}$, and the two extracts were pooled in the dark at room temperature and purified by thin-layer chromatography by using a petroleum ether-acetone-methanol $(82: 16: 2, \mathrm{vol} / \mathrm{vol})$ solvent system.

In vitro amplification of rRNA genes. DNA was used for in vitro amplification of the rRNA gene by the PCR technique (19) in combination with a $16 \mathrm{~S}$ rRNA gene-specific primer pair, 5'-AGTTTGATCCTGGCTC OH-3' (identical to sequence positions 10 to 25 in the Escherichia coli numbering system [1]) and 5'-AAGGAGGTGATCCAGCC OH-3' (complementary to positions 1541 to 1525 ), as described previously (29). Amplification was carried out by using a Taq polymerase kit (Cetus Inc.). The PCR cycle parameters were as follows: preheating for $2.5 \mathrm{~min}$ at $95^{\circ} \mathrm{C}$, denaturation for $1 \mathrm{~min}$ at $94^{\circ} \mathrm{C}$,

1 AgUUUGAUCCUGGCUCAGAACGAACGCUGGCGGCAUGCCUAACACAUGCAAGUCGAACGAGACCUUCGGGUCUAGUGGCGCACGGGUGCGUAACGCGUGG

101 GAAUCUACCCUUGGGUUCGGAAUAACAGUUAGAAAUGACUGCUAAUACCGGAUGAUGACGAAAGUCCAAAGAUUUAUCGCCCAAGGAUGAGCCCGCGUAG

201 GAUUAGCUAGUUGGUGAGGUAAAGGCUCACCAAGGCGACGAUCCUUAGCUGGUCUGAGAGGAUGAUCAGCCACACUGGGACUGAGACACGGCCCAGACUC

301 CUACGGGAGGCAGCAGUGGGGAAUAUUGGACAAUGGGCGAAAGCCUGAUCCAGCAAUGCCGCGUGAGUGAUGAAGGCCUUAGGGUUGUAAAGCUCUUUUA

401 CCCGGGAUGAUAAUGACAGUACCGGGAGAAUAAGCUCCGGCUAACUCCGUGCCAGCAGCCGCGGUAAUACGGAGGGAGCUAGCGUUGUUCGGAAUUACUG

501 GGCGUAAAGCGCACGUAGGCGGCUAUUCAAGUCAGAGGUGAAAGCCCGGGGCUCAACCCCGGAAUAGCCUUUGAAACUAGAUAGCUAGAAUCUGGGAGAG

601 GUGAGUGGAAUUCCGAGUGUAGAGGUGAAAUUCGUAGAUAUUCGGAAGAACACCAGUGGCGAAGGCGGCUCACUGGACCAGAAUUGACGCUGAGGUGCGA

701 AAGCGUGGGGAGCAAACAGGAUUAGAUACCCUGGUAGUCCACGCCGUAAACGAUGAUAACUAGCUGUCUGGGUUCUUAGAACUUAGGUGGCGCACGUAAC

801 GCAUUAAGUUAUCCGCCUGGGGAGUACGGUUGCAAGAUUAAAACUCAAAGGAAUUGACGGGGGCCUGCACAAGCGGUGGAGCAUGUGGUUUAAUUCGAAG

901 CAACGCGCAGAACCUUACCAGCGUUUGACAUCCUCAUCGCGAUUUCCAGAGAUGGAUUUCUUCAGUUCGGCUGGAUGAGUGACAGGUGCUGCAUGGCUGU

1001 CGUCAGCUCGUGUCGUGAGAUGUUGGGUUAAGUCCCGCAACGAGCGCAACCCUCGCCUUUAGUUACCAUCAUUUAGUUGGGUACUCUAAAGGAACCGCCG

1101 GUGAUAAGCCGGAGGAAGGUGGGGAUGACGUCAAGUCCUCAUGGCCCUUACGCGCUGGGCUACACACGUGCUACAAUGGCGGUGACAGUGGGCAGCUAAC

1201 UCGCGAGAGUAUGCUAAUCUCUAAAAACCGUCUCAGUUCGGAUUGUUCUCUGCAACUCGAGAGCAUGAAGGCGGAAUCGCUAGUAAUCGCGGAUCAGCAU

1301 GCCGCGGUGAAUACGUUCCCAGGCCUUGUACACACCGCCCGUCACACCAUGGGAGUUGGAUUCACCCGAAGGCGCUGAGCUAACCCGCAAGGGAGGCAGG

1401 GGACCACGGUGGGUU

FIG. 1. Partial $16 \mathrm{~S}$ rRNA sequence of Rhizomonas suberifaciens. The first and last nucleotides are analogous to positions 10 and 1483 of the Escherichia coli sequence (1). 


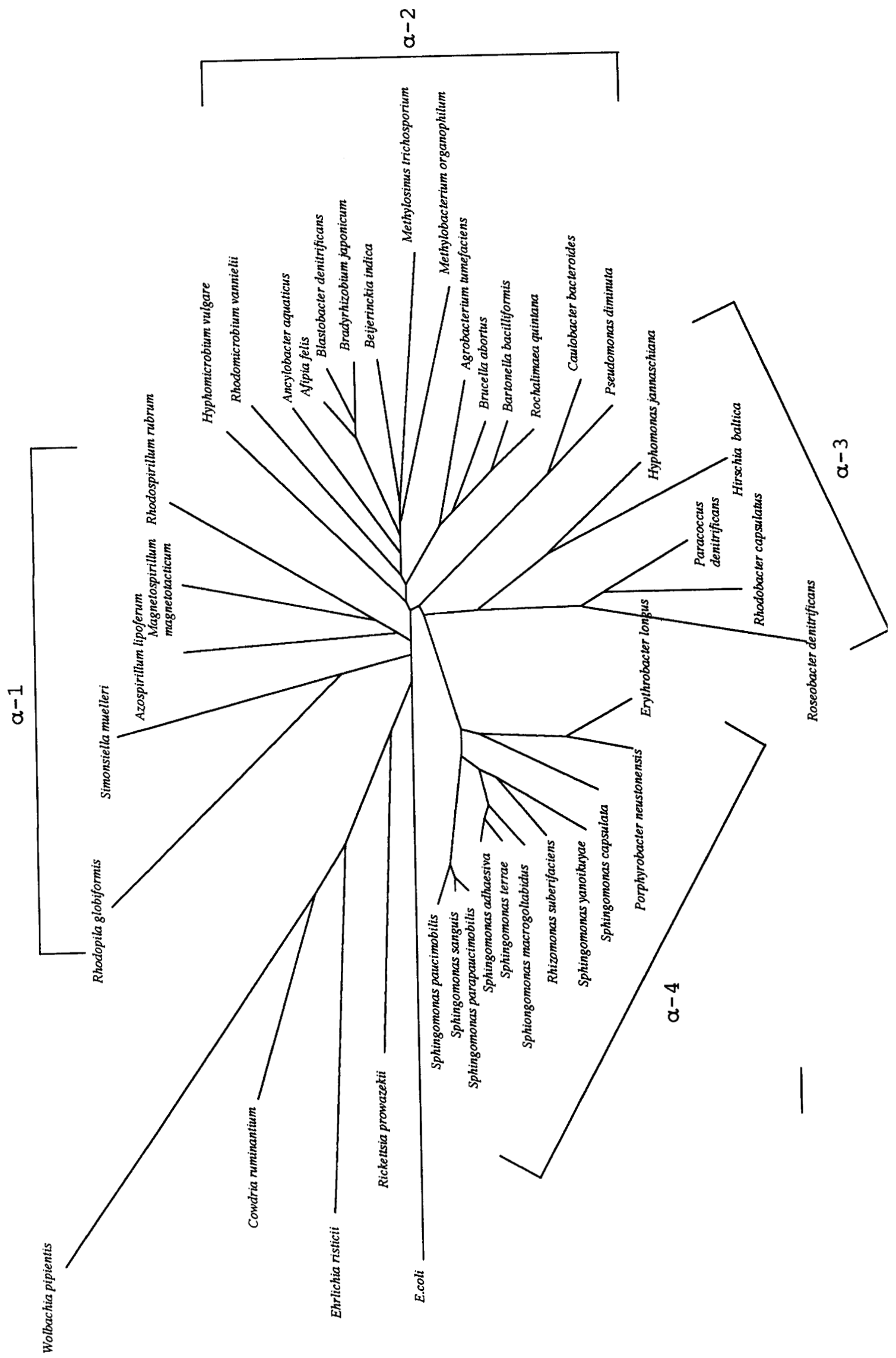


annealing for $2.5 \mathrm{~min}$ at $58^{\circ} \mathrm{C}$, and extension for $2.5 \mathrm{~min}$ at $72^{\circ} \mathrm{C}$. After 30 cycles, the final step was incubation for $5 \mathrm{~min}$ at $72^{\circ} \mathrm{C}$. The lengths of the amplified fragments were determined by agarose $(1 \%, \mathrm{wt} / \mathrm{vol})$ gel electrophoresis.

Sequence determination and analysis. The amplified DNA was purified by using Suprec-01 (Takara Co., Ltd., Shiga, Japan) after electrophoresis on an agarose $(1 \%, \mathrm{wt} / \mathrm{vol}) \mathrm{gel}$. The purified DNA was sequenced by using a Sequenase kit for ${ }^{35}$ S-dATP (United Biochemical Inc.) and the following primers: 5'-AGTTTGATCCTGGCTC OH-3' (identical to positions 10 to 25), 5'-GTGTTACTCACCCGT OH-3' (complementary to positions 123 to 109 ), 5'-TACGGGAGGCAGC AG OH-3' (identical to positions 343 to 357 ), 5'-CTGCTGC CTCCCGTAG OH-3' (complementary to positions 357 to 342), 5'-GTGCCAGCAGCCGCGG OH-3' (identical to positions 515 to 530), 5'-ACCGCGGCTGCTGGC OH-3' (complementary to positions 531 to 517), 5'-TCTACGCATTTC ACC OH-3' (complementary to positions 704 to 690 ), 5'-GTC AATTCCTTTGAGTTT OH-3' (complementary to positions 924 to 907 ), 5'-AGGGTTGCGCTCGTTG OH-3' (complementary to positions 1115 to 1100$), 5^{\prime}$-CCATTGTAGCACGT GT OH-3' (complementary to positions 1242 to 1227 ), 5'-AC GGGCGGTGTGTAC OH-3' (complementary to positions 1406 to 1392), and 5'-GGCTACCTTGTTACGA OH-3' (complementary to positions 1510 to 1495). DNA sequences were aligned by using the ODEN system (7). Nucleotide substitution rates ( $K_{\text {nuc }}$ values) were calculated from all of the available sequence data after alignment (14), and a phylogenetic tree was constructed by the neighbor-joining method (20). The topology of the trees was evaluated by performing a bootstrap analysis of the sequence data, using Clustal V (5).

Nucleotide sequence accession numbers. The sequences were aligned with previously published sequences obtained from the DNA Data Bank of Japan, GenBank, and EMBL data bases and deposited under the following accession numbers: Escherichia coli, M25588; Sphingomonas paucimobilis, D13725; Sphingomonas parapaucimobilis, D13724; Sphingomonas sanguis, D13726; Sphingomonas terrae, D13727; Sphingomonas yanoikuyae, D13728; Sphingomonas adhaesiva, D13722; Sphingomonas capsulata, M59296; Sphingomonas macrogoltabidus, D13723; Erythrobacter longus, M96744; Porphyrobacter neustonensis, M96745; Roseobacter denitrificans, M96746; Afipia felis, M65248; Agrobacterium tumefaciens, M11223; Ancylobacter aquaticus, M62790; Magnetospirillum magnetotacticum, M58171; Azospirillum lipoferum, M59061; Bartonella bacilliformis, M65249; Beijerinckia indica, M59060; Blastobacter denitrificans, X66025; Bradyrhizobium japonicum, X66024; Brucella abortus, X13695; Caulobacter bacteroides, M83796; Cowdria ruminantium, X61659; Ehrlichia risticii, M21290; Erythrobacter longus, M59062; Hirschia baltica, X52909; Hyphomicrobium vulgare, X53182; Hyphomonas jannaschiana, M83806; Methylobacterium organophilum, M29028; Methylosinus trichosporium, M29024; Paracoccus denitrificans, X69159; Porphyrobacter neustonensis, M96745; Pseudomonas diminuta, M59064; Rhodobacter capsulatus, M34129; Rhodomi- crobium vannielii, M34127; Rhodopila globiformis, M59066; Rhodospirillum rubrum, M32030; Rickettsia prowazekii, M21789; Rochalimaea quintana, M11927; Roseobacter denitrificans, M96746; Simonsiella muelleri, M59071; and Wolbachia pipientis, X61768. The nucleotide sequence data for Rhizomonas suberifaciens have been deposited in the DNA Data Bank of Japan data base under accession number D13737.

\section{RESULTS AND DISCUSSION}

Chemotaxonomic characteristics. Gas chromatography and gas chromatography-mass spectrometry analyses of trimethylsilyl derivatives of long-chain bases from Rhizomonas suberifaciens IFO $15211^{\mathrm{T}}$ and Erythrobacter longus IFO $14126^{\mathrm{T}}$ revealed that dihydrosphingosin $\mathrm{d}-20: 1$ was the major component and that d-18:0, d-19:1, and d-21:1 also were present. Erythrobacter longus is a bacteriochlorophyll-containing bacterium, although it does not have photosynthetic activity. We examined whether species of the genus Sphingomonas contain bacteriochlorophyll and confirmed that bacteriochlorophyll was absent in Sphingomonas paucimobilis IFO 14135 ${ }^{\mathrm{T}}$, Sphingomonas capsulata IFO $12533^{\mathrm{T}}$, and Rhizomonas suberifaciens IFO $15211^{\mathrm{T}}$. Thus, we suggest that the presence of bacteriochlorophyll is a distinctive characteristic which distinguishes the genus Erythrobacter from both the genus Sphingomonas and the genus Rhizomonas. Table 1 shows the morphological, physiological, biochemical, and chemotaxonomic characteristics of the genera Sphingomonas and Rhizomonas, and on the basis of these data the two taxa are indistinguishable. All of the strains of both genera were characterized by having isoprenoid quinone Q-10, by having 2-hydroxymyristic acid, and by lacking 3-hydroxy fatty acid. The $\mathrm{G}+\mathrm{C}$ content of the DNA of Rhizomonas suberifaciens IFO $15211^{\mathrm{T}}$ was 58.0 to $63.0 \mathrm{~mol} \%$, and the $\mathrm{G}+\mathrm{C}$ contents of strains of the genus Sphingomonas were 61.6 to $67.8 \mathrm{~mol} \%$.

In general, gram-negative bacteria contain lipopolysaccharide (LPS) (endotoxin) and 3-hydroxy $C_{10}$ to $C_{18}$ fatty acids in their outer membranes. Although 3-OH fatty acids were not detected in Rhizomonas suberifaciens, the presence of LPS in this species has been reported by van Bruggen et al. $(31,32)$. Kawahara et al. reported that Sphingomonas paucimobilis lacks the usual LPS in the outer membrane (10) but contains amphiphilic glycosphingolipid, which might play a role similar to the role of LPS in other gram-negative bacteria (9). In view of these contradictory results, the presence of LPS in Rhizomonas species should be reexamined.

Phylogenetic analyses. To clarify the phylogenetic relationships of the species belonging to the genera Sphingomonas and Rhizomonas and Erythrobacter longus, we determined the $16 \mathrm{~S}$ rRNA sequence of Rhizomonas suberifaciens IFO $15211^{\mathrm{T}}$ (Fig. 1) and compared it with the sequences of eight species belonging to the genus Sphingomonas (29), the sequences of the bacteriochlorophyll-containing bacteria Porphyrobacter neustonensis (4) and Roseobacter denitrificans (22), and the sequences of 30 other species belonging to the alpha subclass

FIG. 2. Unrooted phylogenetic tree showing the relationships of Rhizomonas suberifaciens IFO $15211^{\mathrm{T}}$, Sphingomonas species, and other members of the alpha subclass of the Proteobacteria. The following reference microorganisms were included: alpha-1 group species Rhodopila globiformis (30, 40), Magnetospirillum magnetotacticum (2), and Rhodospirillum rubrum (30, 40); alpha-2 group species Hyphomicrobium vulgare (25), Rhodomicrobium vannielii (40), Ancylobacter aquaticus (39), Afipia felis (37), Blastobacter denitrificans (37), Bradyrhizobium japonicum (37), Methylosinus trichosporium (30), Methylobacterium organophilum (30), Agrobacterium tumefaciens $(30,40)$, Bartonella bacilliformis (18), Rochalimaea quintana (36), Caulobacter bacteroides (27), and Pseudomonas diminuta (30); alpha-3 group species Hyphomonas jannaschiana (25), Hirschia baltica (21), Paracoccus denitrificans $(15,40)$, Rhodobacter capsulatus $(30,40)$, and Roseobacter denitrificans $(4)$; alpha-4 group species Erythrobacter longus (40) and Porphyrobacter neustonensis (4); alpha group species Cowdria ruminantium (3), Ehrlichia risticii (34, 35), Rickettsia prowazekii (35), and Wolbachia pipientis (16); delta-3 group species Escherichia coli $(30)$. Bar $=0.01 K_{\text {nuc }}$ unit. 


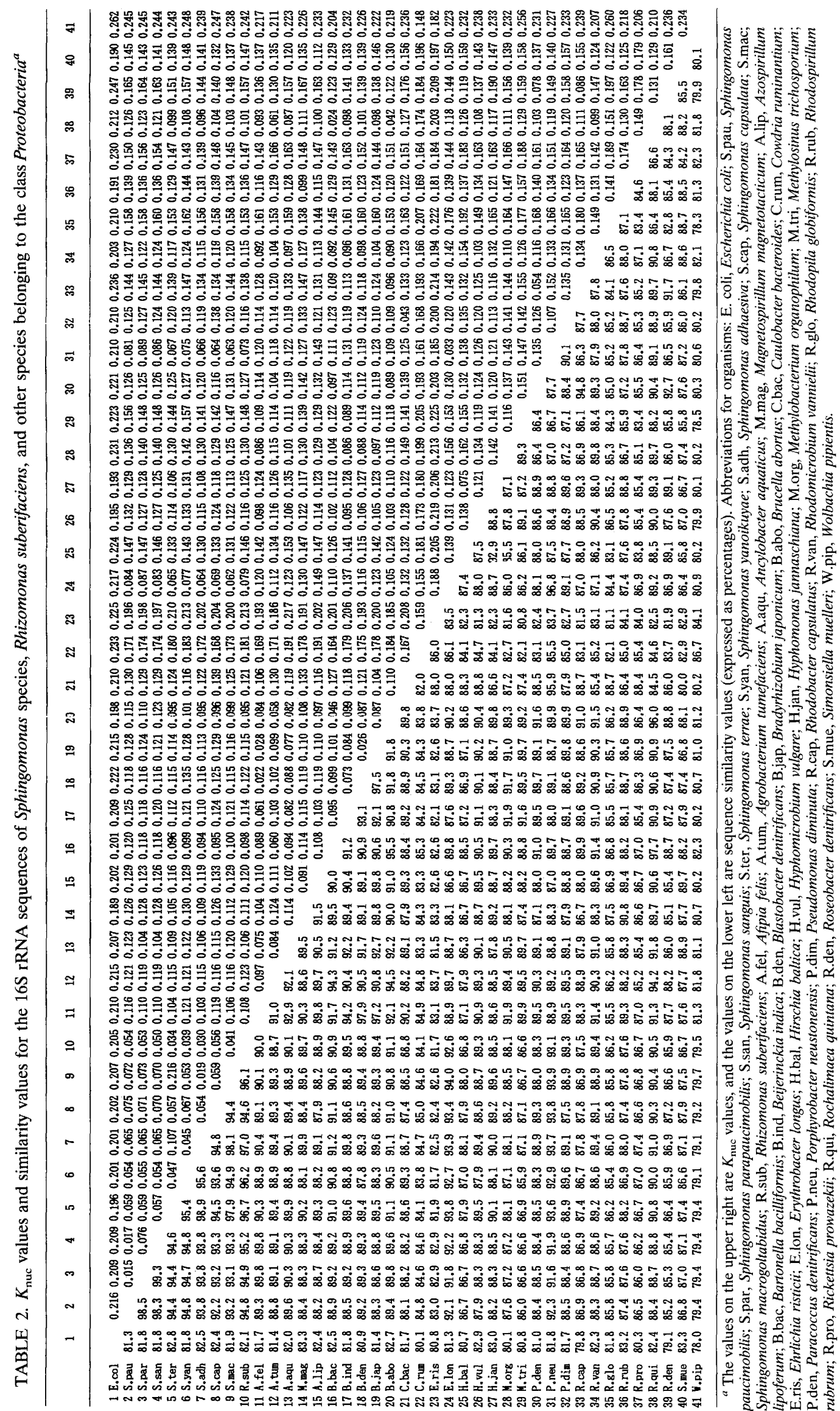


of the Proteobacteria. Figure 2 shows an unrooted phylogenetic tree derived from $K_{\text {nuc }}$ values that were calculated by using 941 bases from 41 species. Table 2 shows the $K_{\text {nuc }}$ and sequence similarity values for Sphingomonas species, Rhizomonas suberifaciens, and other members of the Proteobacteria. As shown in Fig. 2, the branching pattern indicates that Rhizomonas suberifaciens and all of the Sphingomonas species belong in the alpha-4 subclass of the Proteobacteria. Moreover, an analysis of our data confirmed the existence of four major subgroups. The first subgroup consists of Sphingomonas paucimobilis, Sphingomonas parapaucimobilis, and Sphingomonas sanguis (similarity values, 98.3 to $99.3 \%$ ); the second subgroup comprises the polyethylene glycol-utilizing bacteria Sphingomonas macrogoltabidus, Sphingomonas terrae, and Sphingomonas adhaesiva (similarity values, 97.9 to $98.9 \%$ ); the third subgroup consists of Sphingomonas yanoikuyae and Rhizomonas suberifaciens (similarity value, 96.2\%); and the last subgroup contains Sphingomonas capsulata, which is clearly distinct from other species belonging to the genus Sphingomonas (similarity values, 92.2 to $94.8 \%$ ) and Rhizomonas suberifaciens (similarity value, $94.6 \%$ ).

On the basis of the results described above, it is clear that all of the species belonging to the genera Sphingomonas and Rhizomonas are nonphotosynthetic members of the alpha-4 subclass of the Proteobacteria, but these organisms are phylogenetically interrelated and can be divided into several subgroups. The chemotaxonomic characteristics of the two genera are rather similar, and there are few other remarkable differences in morphological and physiological characteristics which distinguish these subgroups.

van Bruggen et al. (33) suggested that Sphingomonas yanoikuyae should be placed in the genus Rhizomonas and that Sphingomonas capsulata should be transfered to a new genus. Our results supported these conclusions. In addition, six other species of the genus Sphingomonas could be divided into two subgroups, each of corresponded to a genus; one subgroup contained the original Sphingomonas species (Sphingomonas paucimobilis, Sphingomonas parapaucimobilis, and Sphingomonas sanguis), and the other contained Sphingomonas adhaesiva, Sphingomonas terrae, and Sphingomonas macrogoltabidus.

However, it is not appropriate to transfer these subgroups to other genera at the present time because of a lack of differential phenotypic characteristics. Thus, a thorough revision of the generic and species classification of this group is inevitable.

\section{ACKNOWLEDGMENTS}

We thank Toru Hasegawa, Institute for Fermentation, Osaka, for his encouragement and support.

Part of this work was supported by Grant-in-Aid for Cooperative Research 03304017 from the Ministry of Education, Japan.

\section{REFERENCES}

1. Brosius, J., J. L. Palmer, J. P. Kennedy, and H. F. Noller. 1978. Complete nucleotide sequence of a 16S ribosomal RNA gene from Escherichia coli. Proc. Natl. Acad. Sci. USA 75:4801-4805.

2. Burgess, J. G., R. Kawaguchi, T. Sakaguchi, R. H. Thornhill, and E. Stackebrandt. 1993. Evolutionary relationships among Magnetospirillum strains inferred from phylogenetic analysis of $16 \mathrm{~S}$ rDNA sequences. J. Bacteriol. 175:6689-6694.

3. Dame, J. B., S. M. Mahan, and C. A. Yowell. 1992. Phylogenetic relationship of Cowdria reminantium, agent of heartwater, to Anaplasma marginale and other members of the order Rickettsiales determined on the basis of $16 \mathrm{~S}$ rRNA sequence. Int. J. Syst. Bacteriol. 42:270-274.

4. Fuerst, J. A., J. A. Hawkins, A. Holmes, L. I. Sly, C. J. Moore, and E. Stackebrandt. 1993. Porphyrobacter neustonensis gen. nov., sp. nov., an aerobic bacteriochlorophyll-synthesizing budding bacte- rium from freshwater. Int. J. Syst. Bacteriol. 43:125-134.

5. Higgins, D. G., A. J. Bleasby, and R. Fuchs. 1992. Clustal V: improved software for multiple sequence alignment. CABIOS 8:189-190.

6. Holmes, B., R. J. Owen, A. Evans, H. Malnick, and W. R. Willcox. 1977. Pseudomonas paucimobilis, a new species isolated from human clinical specimens, the hospital environment, and other sources. Int. J. Syst. Bacteriol. 27:133-146.

7. Ina, Y. 1991. Molecular evolutionary analysis system for DNA and amino acid sequences (ODEN), version 1.1. DNA Data Bank of Japan, DNA Research Center, National Institute of Genetics, Mishima, Japan.

8. Jantzen, E., and K. Bryn. 1985. Whole-cell and lipopolysaccharide fatty acids and sugars of gram-negative bacteria. Soc. Appl. Bacteriol. Tech. Ser. 20:145-171.

9. Kawahara, K., U. Seydel, M. Matsuura, H. Danbara, E. T. Rietschel, and U. Zahringer. 1991. Chemical structure of glycosphingolipids isolated from Sphingomonas paucimobilis. FEBS Lett. 292:107-110.

10. Kawahara, K., K. Uchida, and K. Aida. 1982. Isolation of an unusual 'lipid A' type glycolipid from Pseudomonas paucimobilis. Biochim. Biophys. Acta 712:571-575.

11. Kawai, F., M. Fukaya, Y. Tani, and K. Ogata. 1977. Identification of polyethylene glycols (PEGs)-assimilable bacteria and culture characteristics of PEG 6,000. J. Ferment. Technol. 55:429-534.

12. Kawai, F., T. Kimura, Y. Tani, and H. Yamada. 1984. Involvement of polyethylene glycol (PEG)-oxidizing enzyme in the bacterial metabolism of PEG. Agric. Biol. Chem. 48:1349-1351.

13. Kawai, F., and H. Yamanaka. 1986. Biodegradation of polyethylene glycol by symbiotic mixed culture (obligate mutualism). Arch. Microbiol. 146:125-129.

14. Kimura, M. 1980. A simple method for estimating evolutionary rates of base substitutions through comparative studies of nucleotide sequences. J. Mol. Evol. 16:111-120.

15. Ludwig, W., G. Mittenhuber, and C. G. Friedrich. 1993. Transfer of Thiosphaera pantotropha to Paracoccus denitrificans. Int. J. Syst. Bacteriol. 43:363-367.

16. O'Neill, S. L., R. Giordana, A. M. E. Colbert, and T. L. Karr. 1992. 16S rRNA phylogenetic analysis of the bacterial endosymbionts associated with cytoplasmic incompatibility in insects. Proc. Natl. Acad. Sci. USA 89:2699-2702.

17. Oyaizu, H., and K. Komagata. 1983. Grouping of Pseudomonas species on the basis of cellular fatty acid composition and the quinone system with special reference to the existence of 3-hydroxy fatty acid. J. Gen. Appl. Microbiol. 29:17-40.

18. Relman, D. A., P. W. Lepp, K. N. Sadler, and T. M. Schmidt. 1992. Phylogenetic relationships among the agent of bacillary angiomatosis, Bartonella bacilliformis, and other alpha-proteobacteria. Mol. Microbiol. 6:1801-1807.

19. Saiki, R. K., D. H. Gelfand, S. Stoffe, S. J. Scharf, R. Higuchi, G. T. Horn, K. B. Mullis, and A. Erlich. 1988. Primer-directed enzymatic amplification of DNA with a thermostable DNA polymerase. Science 239:487-491.

20. Saitou, N., and M. Nei. 1987. The neighbor-joining method: a new method for reconstructing phylogenetic trees. Mol. Biol. Evol. 4:406-425.

21. Schlesner, H., C. Bartels, M. Sittig, M. Dorsch, and E. Stackebrandt. 1990. Taxonomic and phylogenetic studies on a new taxon of budding, hyphal Proteobacteria, Hirschia baltica gen. nov., sp. nov. Int. J. Syst. Bacteriol. 40:443-451.

22. Shiba, T. 1991. Roseobacter litoralis gen. nov., sp. nov., and Roseobacter denitrificans sp. nov., aerobic pink-pigmented bacteria which contain bacteriochlorophyll $a$. Syst. Appl. Microbiol. 14: $140-145$.

23. Shiba, T., and U. Simidu. 1982. Erythrobacter longus gen. nov., sp. nov., an aerobic bacterium which contains bacteriochlorophyll $a$. Int. J. Syst. Bacteriol. 32:211-217.

24. Shimada, K., H. Hayashi, and M. Tasumi. 1985. Bacteriochlorophyll-protein complexes of aerobic bacteria, Erythrobacter longus and Erythrobacter species OCh114. Arch. Microbiol. 143:244-247.

25. Stackebrandt, E., A. Fischer, T. Roggentin, U. Bomar, and J. Smida. 1988. A phylogenetic survey of budding and/or prosthecate, non-phototrophic eubacteria: membership of Hyphomicro- 
bium, Hyphomonas, Pedomicrobium, Filomicrobium, Caulobacter and "Dichotomicrobium" to the alpha-subdivision of purple nonsulfur bacteria. Arch. Microbiol. 42:270-274.

26. Stackebrandt, E., R. G. E. Murry, and H. G. Truper. 1988 Proteobacteria classis nov., a name for the phylogenetic taxon that includes the "purple bacteria and their relatives." Int. J. Syst. Bacteriol. 38:321-325.

27. Stahl, D. A., R. Key, B. Flesher, and J. Smit. 1992. The phylogeny of marine and freshwater Caulobacter reflects their habitat. J. Bacteriol. 174:2193-2198.

28. Stal, L. J., H. van Gemerden, and W. E. Krumbein. 1984. The simultaneous assay of chlorophyll and bacteriochlorophyll in natural microbial communities. J. Microbiol. Methods 2:295-306.

29. Takeuchi, M., F. Kawai, Y. Shimada, and A. Yokota. 1993. Taxonomic study of polyethylene glycol-utilizing bacteria: emended description of the genus Sphingomonas and new description of Sphingomonas macrogoltabidus sp. nov., Sphingomonas sanguis sp. nov. and Sphingomonas terrae sp. nov. Syst. Appl. Microbiol. 16:227-238.

30. Tsuji, K., H. C. Tsien, R. S. Hanson, S. R. DePalma, R. Scholtz, and $\bullet$. LaRoche. 1990. 16S ribosomal RNA sequence analysis for determination of phylogenetic relationship among methylotrophs. J. Gen. Microbiol. 136:1-10.

31. van Bruggen, A. H. C., R. G. Grogan, C. P. Bogdanoff, and C. M. Waters. 1988. Corky root of lettuce in California caused by a gram-negative bacterium. Phytopathology 78:1139-1145.

32. van Bruggen, A. H. C., K. N. Jochimsen, and P. Brown. 1990. Rhizomonas suberifaciens gen. nov., sp. nov., the causal agent of corky root of lettuce. Int. J. Syst. Bacteriol. 40:175-188.

33. van Bruggen, A. H. C., K. N. Jochimsen, E. M. Steinberger, P. Segers, and M. Gillis. 1993. Classification of Rhizomonas suberifaciens, unnamed Rhizomonas species, and Sphingomonas spp. in rRNA superfamily IV. Int. J. Syst. Bacteriol. 43:1-7.

34. Weisburg, W. G., S. M. Barns, D. A. Pelletier, and D. J. Lane. 1991. 16S ribosomal DNA amplification for phylogenetic study. J. Bacteriol. 173:697-703.
35. Weisburg, W. G., M. E. R. Dobson, J. E. Samuel, G. A. Dasch, L. P. Mallavia, O. Baca, L. Mandelco, J. E. Sechrest, E. Weiss, and C. R. Woese. 1989. Phylogenetic diversity of the rickettsiae. J. Bacteriol. 171:4202-4206.

36. Weisburg, W. G., C. R. Woese, M. E. Dobson, and E. Weiss. 1985. A common origin of rickettsiae and certain plant pathogens. Science 230:556-558.

37. Willems, A., and M. D. Collins. 1992. Evidence for a close genealogical relationship between Afipia (the causal organism of cat scratch disease), Bradyrhizobium japonicum and Blastobacter denitrificans. FEMS Microbiol. Lett. 96:241-246.

38. Woese, C. R. 1987. Bacterial evolution. Microbiol. Rev. 51:221271.

39. Woese, C. R., S. Maloy, L. Mandelco, and H. D. Raj. 1990. Phylogenetic placement of the Spirosomaceae. Syst. Appl. Microbiol. 13:19-23.

40. Woese, C. R., E. Stackebrandt, W. G. Weisburg, B. J. Paster, M. T. Madigan, V. J. Fowler, C. M. Hahn, P. Blanz, R. Gupta, K. H. Nealson, and G. E. Fox. 1984. The phylogeny of purple bacteria: the alpha subdivision. Syst. Appl. Microbiol. 5:315-326.

41. Yabuuchi, E., E. Tanimura, A. Ohyama, I. Yano, and A. Yamamoto. 1979. Flavobacterium devorans ATCC 10829, a strain of Pseudomonas paucimobilis. J. Gen. Appl. Microbiol. 25:95-107.

42. Yabuuchi, E., I. Yano, H. Oyaizu, Y. Hashimoto, T. Ezaki, and H. Yamamoto. 1990. Proposals of Sphingomonas paucimobilis gen. nov. and comb. nov., Sphingomonas parapaucimobilis sp. nov., Sphingomonas yanoikuyae sp. nov., Sphingomonas adhaesiva sp. nov., Sphingomonas capsulata comb. nov., and two genospecies of the genus Sphingomonas. Microbiol. Immunol. 34:99-119.

43. Yamamoto, A., I. Yano, M. Masui, and E. Yabuuchi. 1978. Isolation of novel sphingoglycolipid containing glucuronic acid and 2-hydroxy fatty acid from Flavobacterium devorans ATCC 10829. J. Biochem. 83:1213-1216.

44. Yano, I., I. Tomiyasu, and E. Yabuuchi. 1982. Long chain base composition of strains of three species of Sphingobacterium gen. nov. FEMS Microbiol. Lett. 15:303-307. 